\title{
Methylation of CDX2 gene promoter in the prediction of treatment efficacy in colorectal cancer
}

\author{
YUNSHUAI WANG, ZHAOHUI LI, WENXIAN LI, SHUAIFENG LIU and BAOWEI HAN \\ Department of Gastrointestinal Surgery, Luoyang Central Hospital Affiliated to \\ Zhengzhou University, Luoyang, Henan 471000, P.R. China
}

Received July 19, 2016; Accepted March 29, 2017

DOI: $10.3892 / \mathrm{ol} .2018 .8670$

\begin{abstract}
The aim of the present study was to examine the diagnosis of methylation of CDX2 gene promoter in colorectal cancer (CRC) and assessed its value in the prediction of treatment efficacy. Sixty patients who were diagnosed as CRCs for the first time, 60 patients with hyperplastic polyps (HPs) and adenomas, and 60 patients with inflammatory lesions or healthy patients (control group) were included in the present study. The methylation levels of CDX2 gene promoter were detected by methylation-specific polymerase chain reaction (MSP), and the expression levels of CDX2 mRNA were detected by fluorescence quantitative PCR. Treatment options, such as surgery, radiotherapy and chemotherapy, were chosen on the basis of TNM staging of CRC patients. The tumor-free survival, relapse rate and mortality were also recorded. The methylation rate was $71.67 \%$ (43/60) and significantly higher in the CRC group as compared to the HP/adenoma and control groups, $\mathrm{P}<0.05$. Moreover, they showed further increase with higher degree of TNM staging. The expression levels of CDX2 mRNA was significantly lower in the CRC group in comparison to HP/adenoma and control groups, $\mathrm{P}<0.05$, and showed a further decrease with a higher degree of TNM staging. The tumor-free survival was shorter, and the relapse rate and mortality were higher in patients with positive methylation in the CRC group, $\mathrm{P}<0.05$. Multivariate logistic regression analysis demonstrated that TNM staging and positive methylation were independent risk factors of mortality. In conclusion, higher methylation degree of CDX2 gene promoter resulted in decreased expression of $\underline{C D X 2}$ gene, and was closely associated with TNM staging and prognosis. TNM staging and positive methylation were independent risk factors of mortality for CRC patients.
\end{abstract}

Correspondence to: Dr Baowei Han, Department of Gastrointestinal Surgery, Luoyang Central Hospital Affiliated to Zhengzhou University, 288 Zhongzhou Middle Road, Luoyang, Henan 471000, P.R. China

E-mail: rh97976365haoye@163.com

Key words: colorectal cancer, $C D X 2$ gene, methylation of promoter

\section{Introduction}

Colorectal cancer (CRC) is ranked 3rd in males and 2nd in females with respect to the incidence of malignancy globally. However, it is ranked as 4th with respect to the incidence of mortality. With increasing prevalence and a trend of young age, CRC has now become a great threat to human life (1).

The pathogenesis mechanisms of CRC include direct infiltration and transformation of carcinoma in situ, 'adenoma - adenocarcinoma' classical APC pathway and 'hyperplastic polyps (HPs)-serrated adenoma - carcinoma' serrated pathway, which accounted for $35 \%$, and HP accounted for $75 \%$ of total serrated lesions (2). The serrated pathway was a continuously accumulated process with multiple factors, segments and genes, and abnormal methylation of gene promoter and loss of heterozygous genes were very common (3). Type A and C methylation of genes occurred. Type A was associated with age, increasing age lead to higher frequency of methylation; type $\mathrm{C}$ was associated with tumor, abnormal methylation caused the downregulation or silencing of relevant genes, and promoted the pathogenesis of tumor (4). Currently, the abnormal methylation of many genes, such as PCDH- $\gamma-A 12$, SLC19A1, CREB and CYLD, has been related to the pathogenesis of serrated lesion in CRC (5). In addition, CDX2 is an important specific nuclear transcription factor in gastrointestinal abnormality, and involved in the pathogenesis and development of gastric cancer and CRC (6).

The present study examined whether abnormal methylation of CDX2 was related to serrated lesion and clinical efficacy of $\mathrm{CRC}$, and provide sensitive and precise measurement for the early diagnosis and prognosis of CRC.

\section{Patients and methods}

Patient information. Sixty patients who were diagnosed as CRC for the first time, 60 patients with HPs and adenomas, and 60 patients with inflammatory lesions or healthy patients (control group) were included in this study from January 2013 to January 2016. All these conditions were confirmed pathologically. Patients with colorectal metastases, primary malignancy in other site or insufficient clinical information were excluded. The Institutional Ethics Committee approved the above study and informed consent 
Table I. MSP primers.

Primers

Sequences

Length of products (bp)

Forward methylation-specific primers

5'-CGAAAATAAATCACTACGACG-3'

200

Forward non-methylation-specific primers

5'-ATTCAAAATAAAAATCACTACAACA-3'

204

Universal reverse primers

5'-AAAGGATATTGGAGAGTATTTTAG-3'

MSP, methylation-specific polymerase chain reaction.

was obtained from the patients. The CRC group included 36 males and 24 females, with a mean age of $56.7 \pm 13.3$ years; 13 patients of TNM stage intermediate-I, 20 patients of stage II, 15 patients of stage III and 12 patients of stage IV; mean tumor length, $1.8 \pm 0.5 \mathrm{~cm}$ and mean number of tumor lesion, 1.3 \pm 0.4 . The HP and adenoma group included 33 males and 27 females with a mean age of $55.8 \pm 14.5$ years. The control group comprised 32 males and 28 females, mean age of $56.8 \pm 15.2$ years. The sex and age between the 3 groups were comparable.

\section{Methods}

Methylation level of CDX2 gene promoter detected by methylation-specific polymerase chain reaction (MSP). Extraction of DNA in samples was performed as instructed in extraction kit for Animal Genome (Axygen Biosciences, Inc., Union City, CA, USA). Modification of DNA by bisulfite was performed as instructed in kit for MethylDetector Bisulfite Modification (Active Motif, Carlsbad, CA, USA). Methylation-specific primers were designed according to the instructions (Table I). The reaction system (25 $\mu \mathrm{l})$ of MSP included $8.5 \mu 1 \mathrm{ddH}_{2} \mathrm{O}, 2 \mu \mathrm{l}$ modified DNA, $12.5 \mu 1$ Premix Ex Taq DNA polymerase mixture and $2 \mu \mathrm{l}$ methylation-specific or non-methylation-specific primers.

PCR reactions were: $95^{\circ} \mathrm{C}$ for $3 \mathrm{~min} ; 95^{\circ} \mathrm{C}$ for $30 \mathrm{sec}$; $58^{\circ} \mathrm{C}$ for $30 \mathrm{sec} ; 72^{\circ} \mathrm{C}$ for $30 \mathrm{sec} ; 30$ cycles, extension at $72^{\circ} \mathrm{C}$ for $10 \mathrm{~min}$, and stored at $4^{\circ} \mathrm{C}$. PCR products were extracted after gel electrophoresis and sequenced (Invitrogen Life Technologies, Carlsbad, CA, USA). The interpretation criteria of electrophoresis were: Positive amplification with methylation-specific primers and negative amplification with non methylation-specific primers indicated complete methylation, recorded as positive methylation; positive amplification with methylation-specific primers and positive amplification with non methylation-specific primers indicated partial methylation, also recorded as positive methylation; negative amplification with methylation-specific primers and positive amplification with non methylation-specific primers indicated no methylation, recorded as negative methylation.

Expression level of CDX2 $\mathrm{mRNA}$ detected by fluorescence quantitative PCR. Total RNA was extracted using TRIzol reagent. The concentration and purity of extracted RNA were measured by a UV spectrophotometer, and the integrity extracted RNA was detected by agarose gel electrophoresis. Reverse transcription of cDNA was performed with a Takara PrimeScript $^{\circledR}$ 1st Strand cDNA Synthesis kit (Takara Bio, Inc., Otsu, Japan). The primers against CDX2 DNA (Pubmed) were designed with Primer Premier 5 software (Premier Biosoft,
Palo Alto, CA, USA) and aligned in Blast to verify the specificity. The primers used were (Table I): CDX2 forward, 5'-CCGAGCCCTACGGTGCCT-3' and reverse, 5'-GGAATCG CTGTCGTTGAAA-3'; internal control GAPDH forward, 5'-TGGGTGTGAACCACGAGAA-3' and reverse, 5'-GGCAT GGACTGTGGTCATGA-3'. The RT-PCR reaction system (20 $\mu \mathrm{l}$ ) included $10 \mu \mathrm{l}$ Taq enzyme mix, $1 \mu \mathrm{l}$ forward primer and $1 \mu \mathrm{l}$ reverse primer, $6 \mu \mathrm{l}$ enzyme-free $\mathrm{H}_{2} \mathrm{O}$. The RT-PCR procedure used was: Pre-denaturation at $95^{\circ} \mathrm{C}, 3 \mathrm{~min}$; denaturation at $94^{\circ} \mathrm{C}, 30 \mathrm{sec}$; annealing at $57^{\circ} \mathrm{C}, 30 \mathrm{sec}$; extension at $72^{\circ} \mathrm{C}, 30 \mathrm{sec}$; extension at $72^{\circ} \mathrm{C}, 5 \mathrm{~min} ; 35$ cycles, and stored at $4^{\circ} \mathrm{C}$. Agarose gel electrophoresis was performed at a voltage of $100 \mathrm{~V}$ for $28 \mathrm{~min}$. A gel imager (Fotodyne Inc., Hartland, WI, USA) was used for observation. The results are represented using the $2^{-\Delta \Delta \mathrm{Cq}}$ method.

Treatment of $C R C$. Treatment options, such as surgery, radiotherapy and chemotherapy, were selected on the basis of TNM staging. For stage I and II CRC, laparotomy- or laparoscopy-assisted resection of tumor was preferred, and adjunctive radiotherapy and chemotherapy were used according to lymph node metastasis. For stage III and IV CRC, a combination of adjunctive radiotherapy/chemotherapy, surgical resection or palliative treatment and post-operative radiotherapy/ chemotherapy was provided, and the patients were advised to complete at least 3 cycles of radiotherapy/chemotherapy. Median follow-up was 25 months (range, 5-40 months), and the tumor-free survival, relapse rate and mortality were recorded.

Statistical analysis. SPSS 20.0 statistical software (IBM SPSS, Armonk, NY, USA) was used for statistical analysis. Measurement data are presented by mean \pm standard deviation, comparison between groups was performed by one-way analysis of variance (ANOVA), and pairwise comparison was performed by LSD-t-test. Categorical data are presented by number or percentage (\%), comparison between groups was performed by Chi-square test. Survival analysis was performed with Kaplan-Meier survival curve and log-rank Chi-square test. Factors for survival outcome were analyzed by the logistic regression model, and the factors were screened by a backward stepwise method (inclusion criteria $\alpha \leq 0.10$; exclusion criteria $\alpha<0.05)$. $\mathrm{P}<0.05$ was considered to indicate a statistically significant difference.

\section{Results}

Methylation levels of CDX2 promoter. The methylation rate was $71.67 \%(43 / 60)$ in the CRC group, $55.00 \%(33 / 60)$ in 
Table II. Survival outcome of CRC patients.

\begin{tabular}{lcccc}
\hline & & $\begin{array}{c}\text { Tumor-free } \\
\text { survival } \\
(\text { months })\end{array}$ & $\begin{array}{c}\text { Relapse rate } \\
(\mathrm{n}, \%)\end{array}$ & $\begin{array}{c}\text { Mortality } \\
(\mathrm{n}, \%)\end{array}$ \\
\hline $\begin{array}{l}\text { Positive } \\
\text { methylation }\end{array}$ & 43 & 8.2 & $21(48.84)$ & $17(39.53)$ \\
$\begin{array}{l}\text { Negative } \\
\text { methylation } \\
\chi^{2} \text { test }\end{array}$ & 17 & 12.4 & $3(17.65)$ & $2(11.76)$ \\
\begin{tabular}{l} 
P-value \\
\hline
\end{tabular} & & 8.324 & 4.938 & 4.342 \\
& 0.003 & 0.026 & 0.037 \\
\hline
\end{tabular}

CRC, colorectal cancer.

Table III. Multivariate logistic regression analysis.

\begin{tabular}{lccccc}
\hline Factors & $\beta$ & Wald & P-value & OR & $95 \%$ CI \\
\hline Stage II & 0.032 & 3.628 & 0.024 & 1.052 & $0.532-2.324$ \\
Stage III & 0.067 & 4.527 & 0.018 & 1.326 & $0.764-2.105$ \\
Stage IV & 0.124 & 4.958 & 0.013 & 1.754 & $1.231-3.226$ \\
$\begin{array}{l}\text { Positive } \\
\text { methylation }\end{array}$ & 0.231 & 5.326 & 0.010 & 2.135 & $1.526-2.867$ \\
\hline
\end{tabular}

the HP and adenoma group, $16.67 \%(10 / 60)$ in the control group, and the difference between groups was statistically significant, $\chi^{2}=38.253, \mathrm{P}<0.001$. In the CRC group, the methylation rate was $53.85 \%$ (7/13) for stage I patients, $65.00 \%(13 / 20)$ for stage II patients, $80.00 \%(12 / 15)$ for stage III patients and $83.33 \%$ (10/12) for stage IV patients, and the methylation rate increased with worsening malignancy.

Expression levels of CDX2 $m R N A$. The expression levels of CDX2 mRNA were significantly lower in the CRC group $(0.1232 \pm 0.0623)$ than the HP and adenoma group (0.3652 \pm 0.0452$)$, and highest in the control group (0.5684 \pm 0.1124$), \mathrm{F}=13.205, \mathrm{P}<0.001$. In the CRC group, the expression level of CDX2 mRNA was $0.2253 \pm 0.0754$ for stage I patients, $0.1632 \pm 0.0865$ for stage II patients, $0.1126 \pm 0.0562$ for stage III patients and $0.0865 \pm 0.0052$ for stage IV patients, the expression level of CDX2 mRNA increased with worsening malignancy.

Survival outcome of CRC patients. As shown in Table II, in CRC group, the tumor-free survival was shorter, the relapse rate and mortality were higher, $\mathrm{P}<0.05$.

Multivariate logistic regression analysis. As shown in Table III, the CRC patient baseline information (sex, age, TNM staging, maximum tumor size, number of tumors, operation method, radiotherapy and chemotherapy) and the degree of methylation were independent variables, and the survival outcome (mortality) of patients was dependent variable. Multivariate logistic regression analysis demonstrated that
TNM staging (stage I as standard) and positive methylation were independent risk factors of mortality.

\section{Discussion}

CDX2 is a member of caudal-related homeobox gene family and is a specific transcription factor of intestinal epithelial cells in vivo. Mutoh et al reported that $C D X 2$ gene was involved in regulating the expression of intestine-specific genes, the development of intestine as well as the differentiation and proliferation of intestinal epithelial cells (7). The expression of $C D X 2$ gene was high in intestinal metaplasia associated with chronic atrophic gastritis, and abnormal in gastric cancer, indicating that $C D X 2$ gene was related to metastasis from gastric mucosa to epithelium and carcinogenesis of gastric mucosa. Mizoshita et al transfected CDX2 cDNA into the human HT29 CRC cell line to obtain an overexpression of CDX2 proteins (8). As a result, the cellular carcinogenic potential and metastasis potential were significantly decreased, and the sensitivity to apoptosis was significantly increased (8).

The present study showed that the methylation rate $(71.67 \%)$ was significantly higher in the CRC group and increased with a higher degree of TNM staging while the expression level of CDX2 mRNA was significantly lower and decreased with a higher degree of TNM staging. Normal pattern of DNA methylation played important regulatory roles in gene expression, embryonic development, genomic imprinting and X-inactivation (9). DNA methylation occurs predominantly in $\mathrm{GC}$-rich region $(\mathrm{CpG}$ dinucleotide, $\mathrm{CpG}$ island), which was located in gene promoter and first exon, and could regulate gene expression (10). It was previously reported that the CDX2 gene promoter was highly methylated in human MKN45 gastric cancer cell line, and the expression levels of CDX2 mRNA were extremely low and CDX2 protein was not expressed. After incubation with three levels of 5-aza-CdR (inhibitor of methylation) for $72 \mathrm{~h}$, the expression levels of CDX2 mRNA and protein were upregulated in MKN45 cells (11). However, it was reported that the expression of $C D X 2$ gene was related to post-transcriptional regulation, such as the phosphorylation of CDX2 protein, rather than epigenetic modification (DNA methylation, histone acetylation) (12). Kawai et al reported that CDX2 gene promoter was located in two $\mathrm{CpG}$ islands, the upstream $\mathrm{CpG}$ island was significantly methylated (sodium bisulfite - RFLP method, COBRA) but unrelated to the expression of CDX2, while the downstream $\mathrm{CpG}$ island was only methylated in a few CRC cell lines, and was related to the expression of CDX2 directly, i.e., the methylation of downstream region of CDX2 gene promoter caused a significantly decreased expression of CDX2 (13).

The present study further demonstrated that in CRC patients, the tumor-free survival was shorter, the relapse rate and mortality were higher in patients with positive methylation, TNM staging and positive methylation were independent risk factors of mortality. In conclusion, higher methylation degree of CDX2 gene promoter resulted in a decreased expression of CDX2 gene, and was closely related to TNM staging and prognosis. This study had a small sample size and short follow-up, thus further studies are essential in the future. 


\section{References}

1. Yung KW, Yung TT, Chung CY, Tong GT, Liu Y, Henderson J, Welbeck D and Oseni S: Principles of cancer staging. Asian Pac J Surg Oncol 1: 1-16, 2015.

2. Kawasaki K, Kurahara K, Yanai S, Oshiro Y, Yao T, Kobayashi H, Nakamura S, Fuchigami T, Sugai T and Matsumoto T: Colonoscopic features and malignant potential of sessile serrated adenomas: comparison with other serrated lesions and conventional adenomas. Colorectal Dis 18: 795-802, 2016.

3. Johnson DH, Taylor WR, Aboelsoud MM, Foote PH, Yab TC, Cao X, Smyrk TC, Loftus EV Jr, Mahoney DW, Ahlquist DA, et al: DNA methylation and mutation of small colonic neoplasms in ulcerative colitis and Crohn's colitis: implications for surveillance. Inflamm Bowel Dis 22: 15591567,2016

4. Chang HF, Wu CC, Sun CA, Chu CM, Lin FG, Hsieh JF, Hsu $\mathrm{CH}$, Huang $\mathrm{CH}$, Yang T, Tsai YM, et al: Clinical stage and risk of recurrence and mortality: interaction of DNA methylation factors in patients with colorectal cancer. J Investig Med 13: 17-18, 2016.

5. Guo YH, Wang LQ, Li B, Xu H, Yang JH, Zheng LS, Yu P, Zhou AD, Zhang Y, Xie SJ, et al: Wnt/ $\beta$-catenin pathway transactivates microRNA-150 that promotes EMT of colorectal cancer cells by suppressing CREB signaling. Oncotarget: Jun 7, 2016 (Epub ahead of print).

6. Bae JM, Lee TH, Cho NY, Kim TY and Kang GH: Loss of CDX2 expression is associated with poor prognosis in colorectal cancer patients. World J Gastroenterol 21: 1457-1467, 2015.

7. Mutoh H, Hayakawa H, Sakamoto H and Sugano K: Homeobox protein CDX2 reduces Cox-2 transcription by inactivating the DNA-binding capacity of nuclear factor-kappaB. J Gastroenterol 42: 719-729, 2007
8. Mizoshita T, Tsukamoto T, Nakanishi H, Inada K, Ogasawara N, Joh T, Itoh M, Yamamura Y and Tatematsu M: Expression of $\mathrm{Cdx} 2$ and the phenotype of advanced gastric cancers: relationship with prognosis. J Cancer Res Clin Oncol 129: 727-734, 2003.

9. Bird A: DNA methylation patterns and epigenetic memory. Genes Dev 16: 6-21, 2002.

10. Lee MS, McGuffey EJ, Morris JS, Manyam G, Baladandayuthapani V, Wei W, Morris VK, Overman MJ, Maru DM, Jiang ZQ, et al: Association of CpG island methylator phenotype and EREG/AREG methylation and expression in colorectal cancer. Br J Cancer 114: 1352-1361, 2016.

11. Zhang JF, Qu LS, Qian XF, Xia BL, Mao ZB and Chen WC: Nuclear transcription factor CDX2 inhibits gastric cancer cell growth and reverses epithelial to mesenchymal transition in vitro and in vivo. Mol Med Rep 12: 5231-5238, 2015.

12. Dawson H, Galván JA, Helbling M, Muller DE, Karamitopoulou E, Koelzer VH, Economou M, Hammer C, Lugli A and Zlobec I: Possible role of $\mathrm{Cdx} 2$ in the serrated pathway of colorectal cancer characterized by BRAF mutation, high-level CpG island methylator phenotype and mismatch repair-deficiency. Int $\mathrm{J}$ Cancer 134: 2342-2351, 2014.

13. Kawai H, Tomii K, Toyooka S, Yano M, Murakami M, Tsukuda K and Shimizu N: Promoter methylation downregulates CDX2 expression in colorectal carcinomas. Oncol Rep 13: 547-551, 2005.

This work is licensed under a Creative Commons Attribution-NonCommercial-NoDerivatives 4.0 International (CC BY-NC-ND 4.0) License. 